\title{
Diagnóstico e modelos de previsão de níveis de ruído e vibração em desmonte de rochas com explosivos
}

\section{Diagnosis And Prediction Models Of Noise And Vibration Levels In Rock Blasting}

Gabriel Fontanelli', Luis Eduardo de Souza ${ }^{2}$, Luciana Arnt Abichequer², Raul Oliveira Neto ${ }^{2}$ Ítalo Gomes Gonçalves²

\author{
${ }^{1}$ Tecnólogo em Mineração, Universidade Federal do Pampa, Caçapava do Sul, RS, Brasil \\ 2 Engenheiro(a) de Minas/Professor do Programa de Pós-Graduação em Tecnologia Mineral (PPGTM), Universidade Federal do \\ Pampa, Caçapava do Sul, RS, Brasil
}

\begin{abstract}
Resumo
O emprego de explosivos é, sem sombra de dúvidas, a maneira mais eficiente e economicamente viável para desmonte de rocha em mineração. No entanto, sabe-se que apenas entre 20 a 30\% da energia dos explosivos é de fato utilizada na fragmentação da rocha, sendo que o restante desta energia acaba provocando impactos ao meio ambiente, tais como ruídos, vibrações, gases, poeira e ultralançamento de rochas. Desta forma, há um risco real para estruturas e pessoal nas vizinhanças de minas ou pedreiras, em particular, quando não há uma preocupação quanto a aspectos relacionados com o planejamento do desmonte. Este trabalho busca, através de monitoramentos dos desmontes de rocha, mensurar e prever a sobrepressão acústica na região mineradora de Caieiras, em Caçapava do Sul, já que trabalhos realizados anteriormente apresentaram resultados que ultrapassaram os limites estipulados pelas normas NRM 16 e NBR 9653/2005. Os monitoramentos são feitos no mesmo local dos trabalhos anteriores, porém o diferencial é a utilização de métodos para diminuir a sobrepressão acústica, cobrindo os cordéis detonantes com material areno-argiloso ou com a substituição dos mesmos por tubos de choque. $O$ monitoramento é feito por microssismógrafo de engenharia, que registra as vibrações e a sobrepressão acústica de cada detonação, além de coletar toda a informação do plano de fogo, principalmente o carregamento dos furos. Os resultados mostraram que, além da utilização dos cordéis e da consequente expulsão dos tampões, os altos valores de sobrepressão acústica, que ultrapassam os 134 decibéis, estavam relacionados com a realização de desmontes secundários.
\end{abstract}

Palavras-chave: Desmonte de rochas, monitoramento, ruídos, vibrações

\begin{abstract}
The use of explosives is an efficient and economically viable way for blasting rock in mining. However, it is know that 20-30\% of the energy of explosives is actually used in rock fragmentation and the rest of this energy ends up causing impacts on the environment such as noise, vibration, gases, dust and flyrocks. Thus, there is a real risk to structures and people around of quarries and mines in general when there is no concern about blasting planning. This work seeks, through the blasting rock monitoring, to measure and predict the acoustic pressure or noise in the region called Caieiras in Caçapava do Sul, since previous works presented results which exceeded the limits prescribed by NRM-16 and NBR-9653/2005. Monitorings were performed and alternatives were tested in order to decrease the noise levels like covering detonating cords with sandy-clay materials, using lighter detonating cords, or even replacing them by shock tubes.
\end{abstract}




\section{Introdução}

A mineração ainda é uma prática econômica básica para o desenvolvimento e conforto das comunidades em todo o mundo, fornecendo matéria-prima para vários outros setores econômicos. Com o crescimento econômico, a mineração tem aumentado a extração dos mais variados tipos de minério, porém a geração de impactos ambientais inflige certo desconforto para comunidades vizinhas, criando conflitos entre as partes atingidas pelos impactos e as empresas mineradoras, ainda mais quando estas estão localizadas próximas de núcleos urbanos. Ao contrário de outras atividades econômicas, a mineração não tem a liberdade da escolha do local de atuação, pois está condicionada à rigidez locacional. Torna-se, então, necessária a elaboração de um bom planejamento de vida da mina e o monitoramento de suas operações. O objetivo é obter o máximo possível de controle dos seus impactos, justificando e compensando a existência da mina como uma atuação segura, lucrativa e sustentável para a sociedade (Scliar, 2009).

O desmonte de rochas com explosivos, principalmente nas minas a céu aberto, é uma das operações que se pode destacar como causa dos impactos mais desconfortantes para o meio ambiente, principalmente para o meio antrópico. Ultralançamento de rochas, vibrações que se propagam pelo solo, ruídos, gases tóxicos e poeira são gerados durante a detonação e podem danificar estruturas ou obras civis, além dos potenciais danos à saúde de pessoas situadas no entorno da frente de lavra (Munaretti et al., 2001).

Segundo Bandhari (1997), embora estes impactos sejam difíceis de controlar por causa de sua variabilidade, muito pode se fazer para amenizá-los. O desenvolvimento do plano de fogo deve levar em consideração todos os fatores geométricos, estruturais, geológicos e ambientais ao ser realizado, devem ser observadas as zonas de fraqueza do maciço rochoso, como falhas, mudanças de litologia, fraturas, qualquer descontinuidade que possibilite possíveis escapes de gás provenientes da decomposição do explosivo. Também devem ser consideradas zonas de risco situadas próximas ao desmonte, incluindo estruturas, equipamentos ou bens materiais que não possam ser removidos antes da detonação. Devem ser calculados o comprimento, diâmetro, afastamento e espaçamento dos furos, bem como a quantidade de explosivo a ser empregada, as cargas de subfuração, o método e a sequência de iniciação de cada furo, os acessórios utilizados e, também, deve haver uma boa comunicação entre os operários e a comunidade, para que não haja acidentes durante as detonações.

Com o objetivo de prever os ruídos e vibrações e meios de amenizá-los através da coleta e a análise de dados, foram realizadas sucessivas campanhas de monitoramento dos desmontes de rochas em uma das empresas mineradoras de calcário da localidade de Caieiras, localizada no município de Caçapava do Sul, em meio à região centro-sul do estado do Rio Grande do Sul (Figura 1). Nesta região, as empresas mineradoras empregam indivíduos da própria região, originando vilas em seu entorno, onde vivem os trabalhadores e suas famílias. Devido a altos níveis de sobrepressão acústica registrados na primeira campanha de monitoramentos, foram utilizadas alternativas na segunda campanha, através da substituição de cordéis com menores diâmetros e da cobertura dos mesmos com uma camada de material areno-argiloso. Também foi utilizada outra alternativa para amenizar os ruídos, envolvendo a substituição dos cordéis por tubos de choque. Além da preocupação com os acessórios, foram pesadas as quantidades de explosivo de cada furo, assim como anotadas todas as informações da geometria do plano de fogo. A partir do levantamento de todas estas informações, foi possível criar modelos de atenuação capazes de auxiliar na previsão dos níveis de vibração e ruídos praticados, além de permitir a otimização do desmonte, com a elaboração de mapas de distribuição de cargas máximas, de acordo com os limites das normas existentes.

\subsection{CARACTERIZAÇÃo DA ÁREA DE ESTUdo}

A mina onde foram realizados os monitoramentos é dividida pela rodovia BR 392, sendo que na parte norte da rodovia estão instalados escritórios e as plantas de beneficiamento do minério (cominuição e calcinação do mármore) e, na parte sul, estão localizadas duas cavas a céu aberto com 
frentes de lavra divergentes, sendo estas denominadas de cava da Corticeira, mais ao norte, e cava do Mangueirão, mais ao Sul (Figura 1). Esta última ainda apresenta duas derivações, denominadas de cava do Cerro e cava da Fontinha.
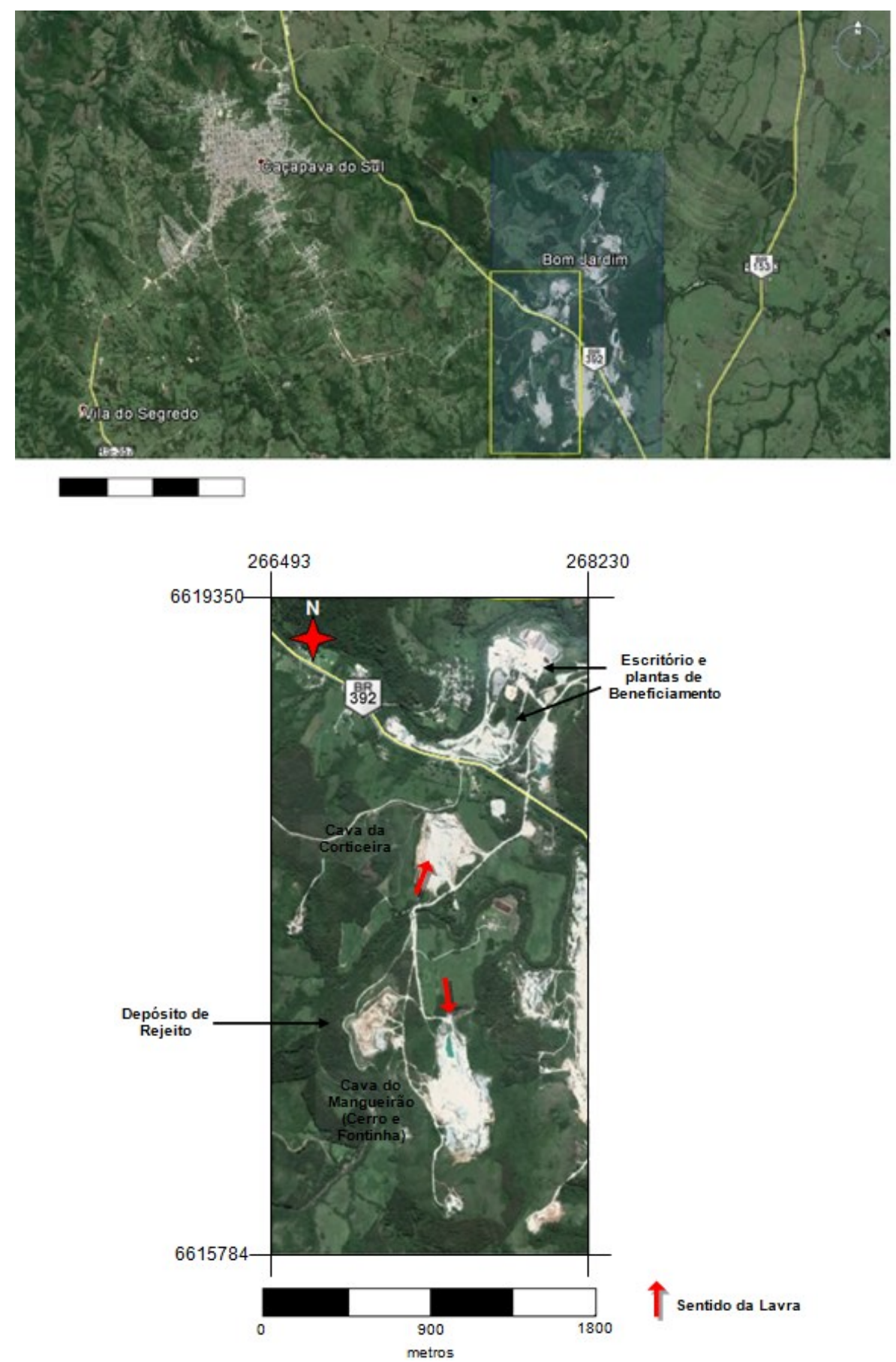

Figura 1 - Localização da região de Caieiras e a área da mina em que foram feitas as campanhas de monitoramento sismográfico. O mapa está nas coordenadas UTM na zona 22J (Fonte: Imagem (C) Digital Globe. (C) Google)

\subsubsection{Geologia Regional}

Na região destacam-se o Complexo Metamórfico do Vacacaí (CMV) do período Neoproterozóico (760 a $730 \mathrm{Ma}$ ), e a Suíte Granítica Caçapava do Sul (SGCS) de aproximadamente $540 \mathrm{Ma}$, ambos localizados no escudo Sul Rio Grandense. A constituição do CMV pode ser associada a duas unidades: 
a metavulcânica e a metavulcanossedimentar. A unidade metavulcânica é composta por rochas como metandesito, metatufo, metavulcanoclástica e níveis de sedimentos metamorfizados nas fácies xisto verde e anfibolito. A unidade metavulcanossedimentar é constituída por lentes de mármore e xistos provenientes de metapelito, grafita xisto, quartzitos, anfibolito e níveis de metavulcânicas intermediárias. Os mármores dolomíticos, que ocorrem em maior volume a leste da SGCS na forma de corpos lenticulares de dimensões variadas, apresentam coloração branco-amarelada, registrando-se ainda a presença de mármores pretos e róseos na porção sul da faixa que contorna a SGCS. Rochas calcissilicáticas, representadas por biotitacarbonato xistos e quartzodiopsídio gnaisses, estão associadas aos corpos carbonáticos, com os quais mostram contatos gradativos. Também há a ocorrência de anfibólio xistos, anfibólio gnaisses, anfibolitos, gnaisses quartzo-feldspáticos, rochas magnesianas e rochas vulcânicas de composição riolítica a riodacítica metamorfizadas, além de rochas anquimetamórficas. A SGCS é constituída principalmente por monzo e sienogranitos, com participação subordinada de rochas de composição granodiorítica a tonalítica representadas principalmente na borda oeste do corpo principal. Pode-se também, considerar os diversos tipos petrográficos em três fácies principais, que classificada como biotita granitóides, leucogranitóides e granitoides transicionais (Porcher \& Lopes, 2000).

Como podemos observar na figura 2, a SGCS tem forma elíptica orientada pelo eixo N-S, com cerca de $25 \mathrm{~km}$ de extensão. Esta compreende dois corpos graníticos intrusivos no CMV, sendo que um dos corpos forma um cinturão metamórfico no entorno da SGCS, caracterizando um metamorfismo regional (Porcher et al., 2000).
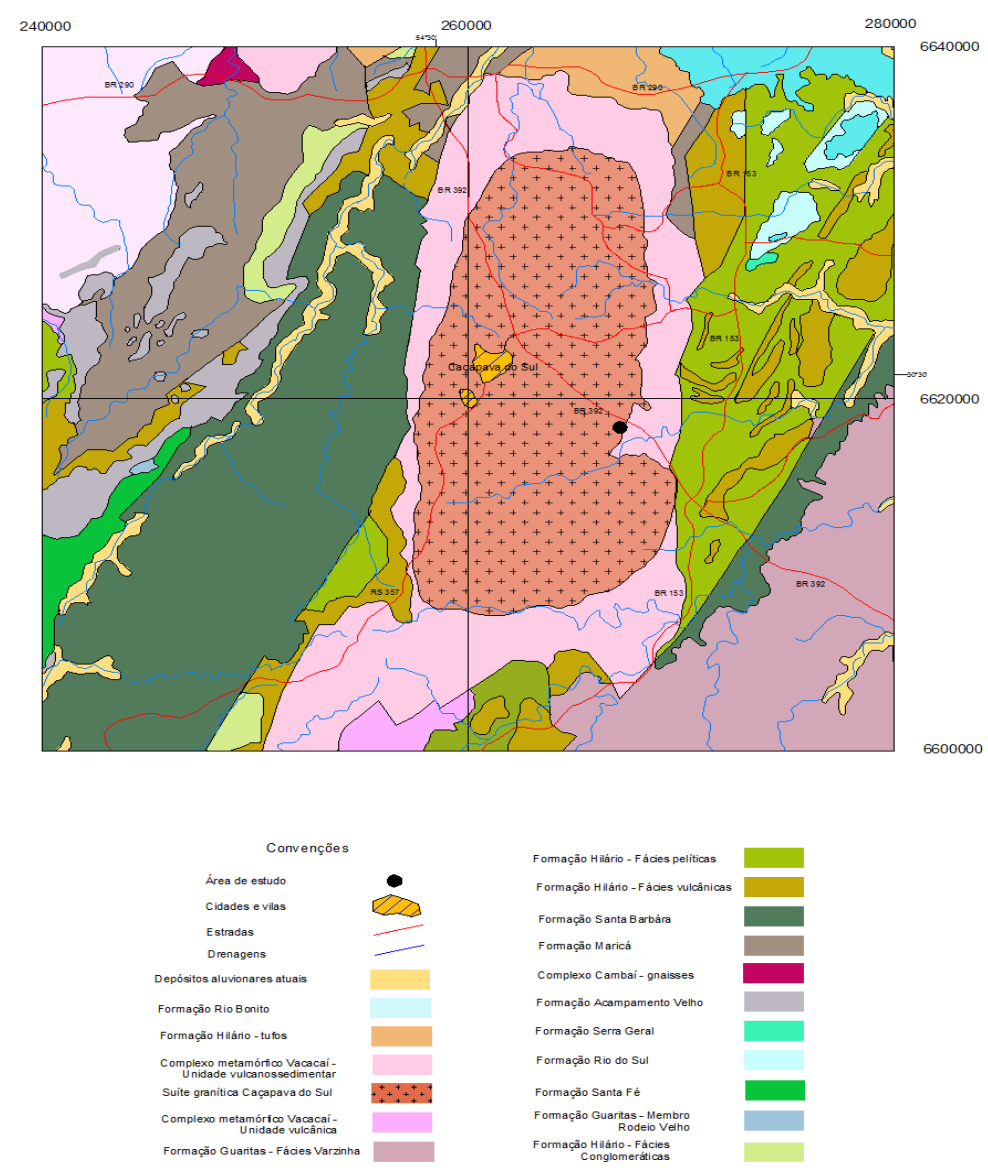

Figura 2 - Mapa geológico regional simplificado (fonte: Dorneles, 2013).

\subsubsection{Geologia Local}


A área de coleta de dados, onde foram feitas as campanhas de monitoramento, encontra-se no Complexo Metamórfico Vacacaí, na unidade metavulcanossedimentar, onde se encontram afloramentos de lentes de mármores (calcário metamorfizado), minério rico em carbonatos (minerais de interesse). Porém também se encontram anfibolitos, mica-xisto, talcoxistos e apófises da SGCS (Porcher et al., 2000).

Para ocorrer a formação do mármore, rochas carbonáticas precisam ser submetidas a pressões e temperaturas elevadas. No caso do depósito que está sendo lavrado, é possível notar outras partículas minerais (argilas e silicatos), consideradas impurezas, que assentaram junto com os minerais de calcita e dolomita e metamorfizaram-se há milhares de anos. Durante a estratificação, geralmente de composição silicática, os minerais considerados impureza formam bandas entre partes de composição carbonática uniforme, possuindo cores esverdeadas e amareladas. Também é possível notar a intrusão de apófises graníticas supergênicas entre as camadas, tanto de maneira concordante como de maneira discordante em relação ao calcário (Figura 3). Observam-se também intrusões de diabásio (formado posteriormente ao granito), intrudidos em sentido discordante àquele do calcário (Porcher et al., 2000).

O depósito, de maneira geral, acompanha o eixo N-S, possuindo composição de forma calcítica $\left(\mathrm{CaCO}_{3}\right)$ e dolomítica $\left(\mathrm{CaMg}\left(\mathrm{CO}_{3}\right)\right)$. Suas diferentes composições químicas os destinam a diferentes empregos. O material calcítico, após passar por processo de calcinação, é empregado na fabricação de cal e argamassa, além disso, a porção que apresenta maior poder neutralizador e baixo percentual de resíduos é enviada para uma usina termelétrica localizada no município de Candiota, onde atua na neutralização das emissões decorrentes da queima do carvão. Já o calcário dolomítico, por apresentar magnésio em sua composição, é empregado como corretivo de solo.

As descontinuidades e fraturas locais além de não tornarem possível a utilização do depósito para fins ornamentais, dificultam a prática do plano de fogo. Não se apresenta uma clara previsão da continuação das intrusões, havendo contatos muito bruscos de diferentes litologias, o que causa grandes desvios em relação às situações para as quais o plano de fogo seria feito.

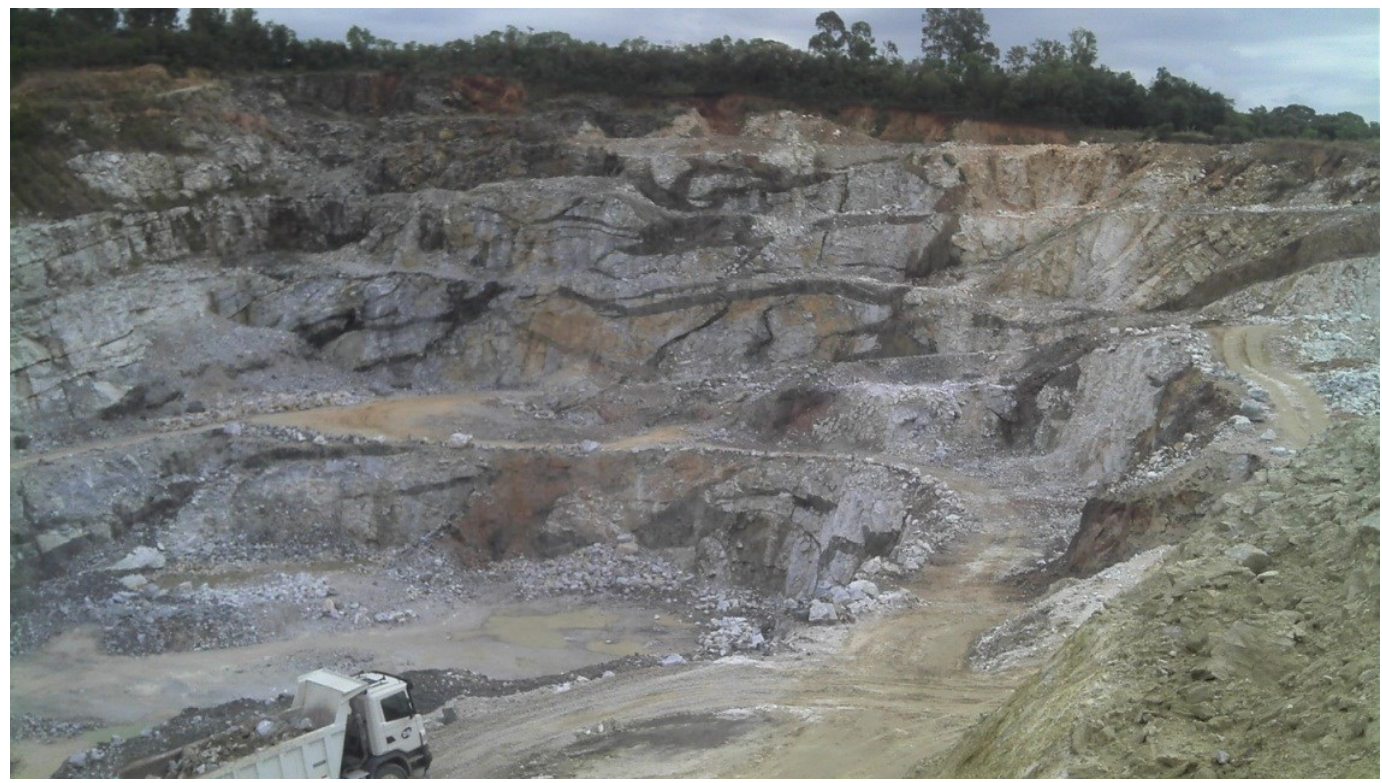

Figura 3 - Depósito da cava da Corticeira, onde se pode observar o grande número de descontinuidades geológicas.

\section{Estado de Arte}

A falta de cuidados específicos em atividades de lavra de empresas mineradoras com a segurança e desconforto ambiental das populações do entorno das minerações e o desinteresse de órgãos fiscalizadores destas atividades, levaram a uma relação pouco amigável entre a comunidade das áreas vizinhas às frentes de extração, os organismos governamentais de controle ambiental e as empresas 
mineradoras. A minimização dos conflitos, buscando uma convivência aceitável entre as atividades de mineração e a comunidade que vive em seu entorno, tem sido mais efetiva através da aplicação, pelas empresas mineradoras, de medidas efetivas de atenuação do impacto ambiental (Dallora Neto \& Ferreira, 2006).

O explosivo é um agente que se decompõe em frações de segundo, gerando grande volume de gás e ondas de choque, provocando a fragmentação das rochas. Porém, como foi salientado anteriormente, somente uma parte da energia dos explosivos (entre 20 a 30\%) é utilizada para esta finalidade, o restante da energia se dissipa, causando impactos ambientais. Os principais impactos causados pelo desmonte de rocha com explosivos são a poeira, a geração de gases tóxicos, as vibrações no solo e a sobrepressão acústica (Persson et al., 1994).

Segundo a U.S. Army Corps of Engineers (1995), a sobrepressão acústica ou ruídos causam objeções públicas e podem quebrar vidros das edificações próximas ao ponto onde ocorre a detonação e podem ser prevenidos utilizando o material de tampão apropriado e evitando detonações durante dias em que as condições climáticas são adversas. Este ainda relata que o aumento da vibração é proporcional à quantidade de explosivo utilizada no desmonte, sendo possível a utilização de acessórios de detonação para atrasar a sequência de iniciação dos furos em uma malha para controlar as vibrações.

Segundo Persson et al. (1994) e Bandhari (1997) alguns fatores podem intensificar a ação dos impactos gerados pelos desmontes de rochas por explosivo. A geração de poeira e gases tóxicos irá sempre ocorrer durante as detonações, sendo necessária a retirada de pessoas da área de impacto até as partículas se dissiparem na atmosfera. Os ultralançamentos de rochas ocorrem por erro de perfuração, disposição errônea do espaçamento e afastamento, sobrecarga de explosivos, tampão inadequado, descontinuidades geológicas e iniciação e sequenciamento defeituosos dos furos. Por mais bem calculado e desenvolvido que o plano de fogo possa ser, ultralançamentos são comuns, já que desmontes não ocorrem em situações ideais, mas, mesmo assim, devem ser minimizados. Já as vibrações que se propagam pelo solo podem ser influenciadas por:

(i) carga máxima por espera: é a maior carga detonada em um mesmo instante, pois a energia de vibração é proporcional à energia liberada na decomposição do explosivo. Pode ser controlada provocando atrasos entre as detonações dos furos por meio de acessórios de detonação;

(ii) grau de confinamento: é influenciado pelo número de faces da bancada, espaçamento e afastamento, cujas dimensões, no caso de serem maiores do que o planejado, acabam aumentando a intensidade deste impacto, pois a energia dos explosivos não seria o suficiente para fragmentar a rocha e se dissipa em vibrações;

(iii) distância da detonação: nem sempre pode ser controlada e sendo calculada por uma linha horizontal (sem levar em consideração altura entre a fonte de detonação e o ponto que sofre vibração). O comum de ocorrer é que distância e vibrações sejam inversamente proporcionais;

(iv) sequência de iniciação: se não calculada corretamente, com atrasos de tempos apropriados, pode ocasionar um fenômeno onde as ondas de cada furo somam-se umas as outras, aumentando o grau de vibração;

(v) contexto geológico: influencia na propagação das ondas, sendo que, quanto mais heterogênea a geologia do terreno (contatos geológicos, falhas, fraturas), maior a resistência contra a propagação das vibrações.

Outro tipo de impacto ambiental que também é uma grande causa de desconforto às comunidades são os ruídos (sobrepressão acústica), influenciados por: 

outras se o atraso for mal calculado, sendo um fator controlável no momento do planejamento de fogo (Figura 4);

(ii) meteorologia: situações de inversão térmica e os ventos podem potencializar a intensidade do ruído em uma certa direção;

(iii) tampão utilizado: deve ser de material e tamanho apropriado (geralmente igual ao comprimento do afastamento) para evitar sua expulsão do furo durante a detonação, pois o tampão serve como um meio resistente à propagação das ondas sonoras, abafando os ruídos;

(iv) tipo de iniciação: o tipo de acessório que que está contido no furo, atravessando o tampão e a carga de coluna até a subfuração, pode ocasionar a expulsão do tampão, principalmente se este acessório conter explosivo em sua composição (cordéis detonantes, por exemplo);

(v) tipo de acessório de detonação: há acessórios que produzem ruídos quando detonados juntamente com o desmonte, como é o caso de acessórios que utilizam explosivos em sua composição. Quando este tipo de acessório não recebe nenhum tipo de isolante acústico, acabam sendo uma das possíveis causas de altos ruídos.

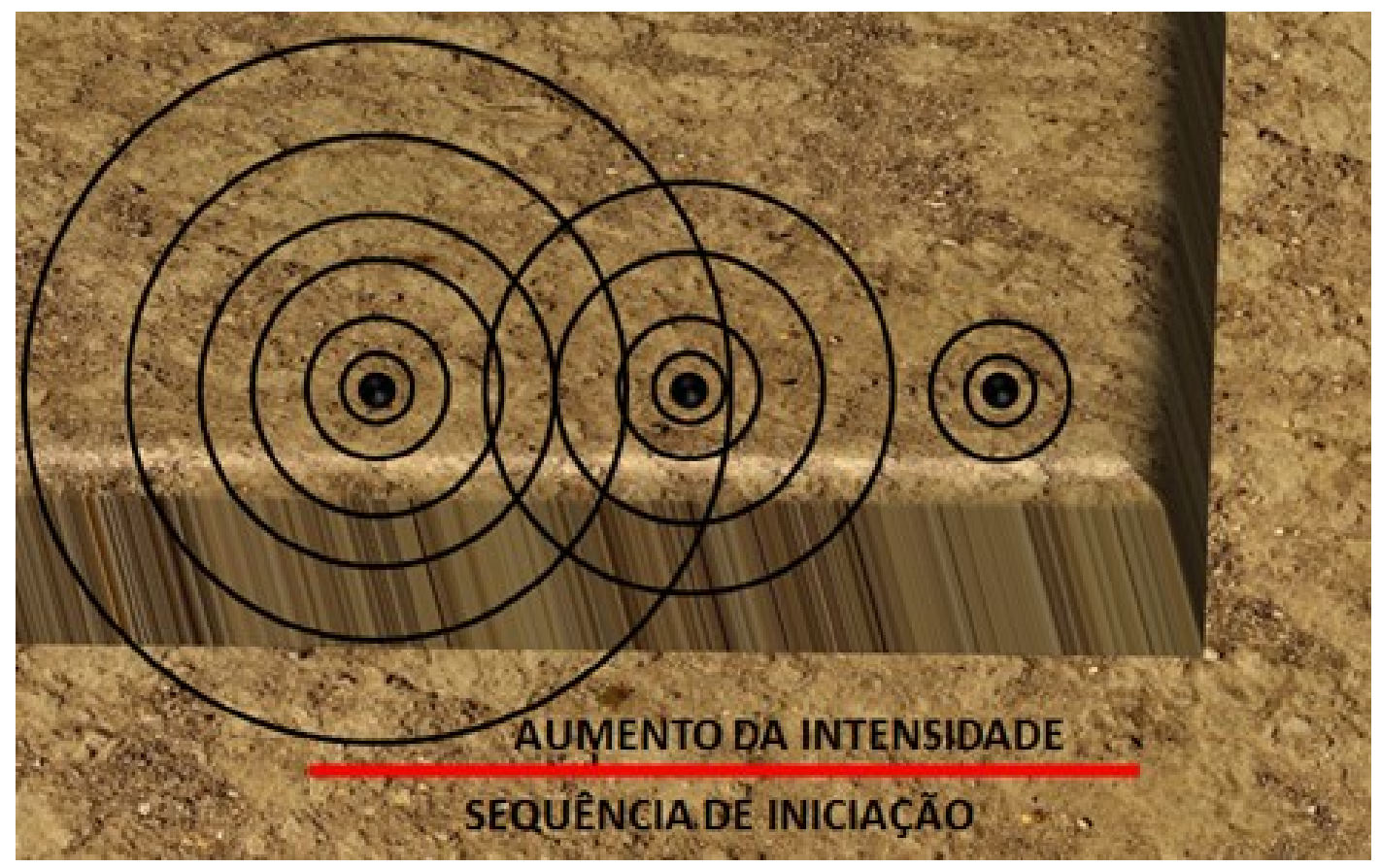

Figura 4 - Aumento da intensidade da vibração, onde se somam as amplitudes de uma onda a outra.

Segundo Persson et al. (1994), os ruídos são causados pela grande quantidade de massa de ar que é movimentada pela detonação. O grau de confinamento do explosivo no furo é determinante, pois a energia que não se dissipar pelas rochas (fragmentando-as ou não), se dissipará na atmosfera, ou seja, quanto maior for o confinamento, menor será a sobrepressão acústica. Há vários mecanismos para que a massa de ar se dissipe através do confinamento:

(i) pulso de pressão de ar: causado diretamente pelo desplacamento da face do talude e da zona de cratera. Quanto mais profundo ou mais confinado estiver o explosivo, mais baixo será este pulso. Tem uma grande amplitude, porém uma baixa frequência quando comparada aos outros tipos de pulso;

(ii) pulso de pressão da rocha: é o primeiro pulso que chega ao equipamento de monitoramento, porém tem uma baixa amplitude e pode ser negligenciada; 
(iii) pulso de liberação de gases: se origina pela decomposição do explosivo para a forma gasosa que provoca aberturas nas fraturas das rochas. Este tipo de pulso chega depois do pulso de pressão de ar, juntamente com o pulso de liberação de tampão. É este que mais perturba e alarma a vizinhança; (iv) pulso de liberação de tampão: é causado pelo escape de gás da ejeção do tampão. É caracterizado por altas frequências de onda que se sobrepõem aos pulsos de pressão de ar.

Contudo, uma das principais causas de ruídos que perturbam e alarmam a vizinhança seriam os cordéis detonantes que, expostos ao ar para ligar os furos, geram ruídos, pois os mesmos são compostos por agentes explosivos. Já para diminuir os riscos da sobrepressão acústica causar danos às estruturas podem ser colocados retardos de $17 \mathrm{~ms}$, por exemplo, sequencialmente em cada furo (Persson et al., 1994).

Quando possível, a previsão dos níveis de vibração deve ser feita em pontos considerados sensíveis em determinados locais da área de lavra. A equação de atenuação permite adequações ao plano de fogo, dentro de critérios técnicos e econômicos, de modo a serem respeitadas as limitações estabelecidas pelas normas vigentes, sendo assim um referencial à adoção de medidas preventivas tanto na manutenção da integridade física das edificações, como nas comunidades próximas, reduzindo os incômodos causados pelas detonações (Dallora Neto \& Ferreira, 2006).

Segundo Persson et al. (1994), o pico de velocidade de partículas (ppv) é considerado indicador confiável para vibrações no solo causadas pela detonação. Este assume que a energia total do movimento do solo gerado em torno de uma explosão varia diretamente com o peso de explosivos detonados e é inversamente proporcional ao quadrado da distância do ponto de detonação.

A velocidade de pico de partícula pode ser estimada na equação 1 :

$$
P P V=\beta(S D)^{\alpha}
$$

$$
S D=\left(D / \omega^{1 / 2}\right)
$$

Onde PPV é a velocidade de pico da partícula ( $\mathrm{mm} / \mathrm{s}), \alpha$ e $\beta$ são constantes específicas da geologia do terreno, e SD é a distância escalonada $\left(\mathrm{m} / \mathrm{Kg}^{1 / 2}\right)$, que pode ser obtida pela equação 2 , onde D é a distância horizontal $(\mathrm{m})$ entre o furo que ocorre a detonação e o receptor e $\omega$ é a carga máxima de explosivo (Kg) detonada em um mesmo instante (Conestoga-Rovers \& Associates, 2007).

Distâncias escalonadas para ruídos são diferentes das vibrações de pico de partícula (equação 3). Ao invés de se usar raiz quadrada, utiliza-se a cúbica (Person et al., 1994).

$$
S D=\left(D / \omega^{1 / 3}\right)
$$

Adhikari (2005) apresenta vários trabalhos utilizando um modelo de atenuação com base em um gráfico de relação entre velocidade de pico de partícula e distância escalonada, ambos em eixos logarítmicos. Este modelo utilizado em análises de risco é associado a desmontes de rochas com explosivos, então, para uma maior segurança, uma medida preventiva é adotada: utilizando uma reta de limite superior. Passando de um modelo mediano (50\% de previsão de acerto) para um modelo mais conservador (95\% de previsão de acerto), torna-se mais segura a prática do desmonte. Cabe salientar que o modelo é feito a partir de vários monitoramentos com as respectivas características das minas, pois tipo de explosivo, a geologia e a geometria do desmonte afetam a grandeza das vibrações.

Rosenhaim et al. (2012) apresenta uma análise de iniciação com espoleta eletrônica para produção de agregados no RS, utilizando também a velocidade de partícula de pico para correlacionar com a distância escalonada, juntamente com uma equação de atenuação para o modelo de vibrações.

A norma NRM-16 do DNPM (Departamento Nacional da Produção Mineral) estabelece limites de segurança para os níveis de vibração e ruído causados pelo uso de explosivos, além de informar uma série de parâmetros para o manuseio, armazenagem e transporte de explosivos. 
A norma da ABNT, NBR 9653 (2005) regula os níveis máximos de vibração no solo e pressão acústica na atmosfera (ruído). Segundo a norma, pressão acústica é definida como sendo aquela provocada por uma onda de choque aérea com componentes na faixa audível $(20 \mathrm{~Hz}$ a $20.000 \mathrm{~Hz})$ e não audíveis, com duração menor do que um segundo. O critério de dano adotado a partir de vibrações no solo é dado pela velocidade de pico de partícula (PPV). A NBR 9653 define parâmetros e limites seguros para os efeitos decorrentes do uso de explosivos, que serão mais bem discutidos no decorrer deste trabalho.

\section{Materiais e Metodologia}

Dorneles (2013) apresenta metodologia utilizada para os monitoramentos realizados durante uma campanha pioneira, para diagnóstico dos níveis de ruído e vibrações, nesta mesma área de estudo. A partir das constatações apontadas pelo autor, de baixos níveis de vibração e altos valores de ruído, é que foi idealizada uma segunda campanha com o objetivo de aferir o modelo de atenuação proposto e para verificar a resposta do ruído à diferentes alternativas técnicas para reduzi-lo.

Em cada campanha foram coletadas trinta medições de níveis de vibrações de solo e sobrepressão acústica gerados pelos desmontes de rochas com explosivos. Estes dados são coletados através de microssismógrafos de engenharia (Geosonics 3000 EZ Plus). Composto basicamente por três partes:

(i) por um geofone, que contém três transdutores ortogonais que são responsáveis por captar as vibrações em três eixos;

(ii) por um microfone, sustentado por uma haste, responsável por captar os ruídos e;

(iii) por uma unidade de armazenamento de dados digitais.

A primeira e a segunda campanha tiveram as vibrações e ruídos coletados de mesma maneira: instalando microssismógrafos de engenharia a certa distância do desmonte, sendo que esta é mensurada através do sistema de coordenadas UTM. Considera-se indiferente o desnível de altitude de até 6 metros, ou seja, a diferença de altitude entre o desmonte e o ponto que o microssismógrafo esta instalado, como representado na figura 5.

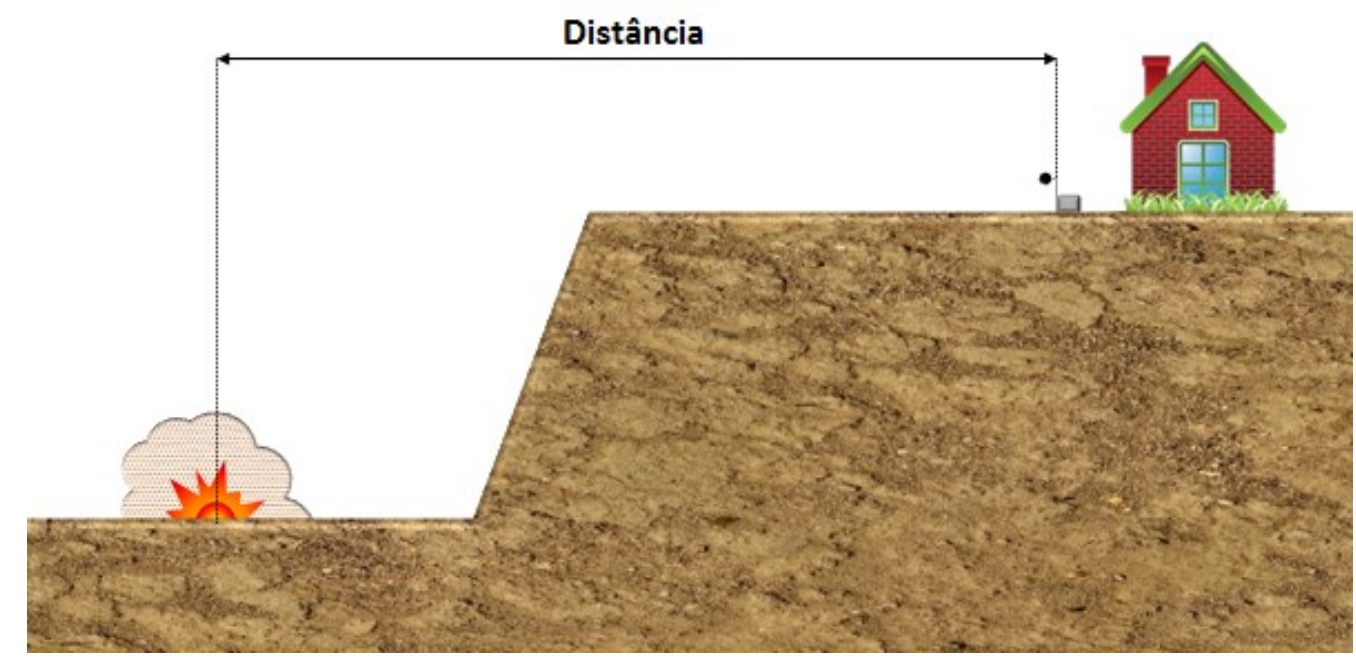

Figura 5 - Representação entre o ponto do desmonte até o ponto de coleta.

Já a coleta de dados das cargas dos furos foi mais detalhada de uma campanha à outra. $\mathrm{Na}$ primeira campanha estimou-se a quantidade de explosivo por furo em média aritmética, através da relação entre a quantidade total de explosivos consumidos e o número de furos do desmonte. Esta 
estimativa não foi coerente com a quantidade real de explosivo em cada furo, já que é comum haver diferentes quantidades em cada um. Na Tabela 1 pode-se observar a diferença, se fosse utilizada a média aritmética, entre a carga máxima por espera estimada e pesada. Com o intuito de aperfeiçoar as estimativas, na segunda campanha foram pesadas as quantidades de cada tipo de explosivo usado no preenchimento de cada furo.

Tabela 1: Comparação entre as diferenças das cargas máximas por espera $(\mathrm{Kg})$ pesadas e estimadas em todos os desmontes monitorados. Os números após algumas das datas são as identificações de desmontes que foram monitorados no mesmo dia.

\begin{tabular}{c|c|c} 
DATA & $\begin{array}{c}\text { CARGA } \\
\text { MÁX./ESPERA } \\
\text { ESTIMADA }\end{array}$ & $\begin{array}{c}\text { CARGA } \\
\text { MÁX./ESPERA } \\
\text { PESADA }\end{array}$ \\
\hline $26 / 11 / 2013$ & 238,88 & 305,65 \\
\hline $29 / 11 / 2013$ & 376,5 & 240 \\
\hline $02 / 12 / 2013$ & 755,11 & 267,85 \\
\hline $12 / 12 / 2013$ & 51,32 & 71,43 \\
\hline $04 / 02 / 2014$ & 128,02 & 140,51 \\
\hline $06 / 02 / 2014$ & 471,14 & 56,26 \\
\hline $11 / 02 / 2014$ & 236,99 & 98,9 \\
\hline $14 / 02 / 2014$ & 119,27 & 216,05 \\
\hline $12 / 03 / 2014$ & 177,75 & 117,64 \\
\hline $25 / 04 / 2014$ & 76,55 & 106,13 \\
\hline $28 / 04 / 2014$ & 117,88 & 118,77 \\
\hline $07 / 05 / 2014(1)$ & 285,89 & 181,21 \\
\hline $07 / 05 / 2014(2)$ & 48,22 & 48,22 \\
\hline $08 / 05 / 2014(1)$ & 418,67 & 418,67 \\
\hline $08 / 05 / 2014(2)$ & 94,21 & 94,21 \\
\hline $09 / 05 / 2014$ & 602,93 & 124,09 \\
\hline $08 / 07 / 2014(1)$ & 106,39 & 75,01 \\
\hline $08 / 07 / 2014(2)$ & 79,03 & 79,03
\end{tabular}

Os explosivos utilizados durante os desmontes monitorados foram: o ANFO (Ammonium Nitrate + Fuel Oil - Nitrato de Amônio + Óleo Combustível) à granel, à uma concentração de 5,2\% de óleo diesel e de $94,8 \%$ nitrato de amônio de baixa densidade, que é utilizado como carga de coluna. Esta concentração têm uma diferença de $0,5 \%$ dos padrões utilizados por Koppe et al. (2008): para fabricar o ANFO é necessário 5,7\% em peso de óleo combustível e 94,3\% de nitrato de amônio no formato à granel do tipo denso (fertilizante) ou baixa densidade (poroso).

Como carga da subfuração é utilizada emulsão encartuchada fabricada por uma indústria especializada. Os explosivos são estocados em um paiol e há o controle para utilizá-los até a data de validade. 
Os cartuchos de emulsão possuem peso padrão de 1,785 quilogramas, sendo necessário apenas multiplicar o peso pela quantidade de cartuchos no furo. O ANFO foi pesado por uma balança digital que pesa até 40 quilogramas a uma precisão de 20 gramas. Foram considerados como dados de plano de fogo as seguintes características: profundidade média dos furos $(\mathrm{m})$, afastamento $(\mathrm{m})$, espaçamento $(\mathrm{m})$, quantidade $(\mathrm{m})$ e diâmetro $(\mathrm{mm})$ de cordel utilizado, quantidade de retardos e de espoletas utilizadas. Além destes dados também foi feito o croqui de cada desmonte, com o respectivo sequenciamento dos furos.

A suspeita da causa dos elevados ruídos da primeira campanha seriam os acessórios de detonação utilizados: cordéis explosivos de $4,8 \mathrm{~mm}$ de diâmetro (NP10) expostos diretamente à atmosfera. Nos monitoramentos da segunda campanha foram utilizados cordéis de 4,8 e 3,8 mm cobertos com uma camada de $10 \mathrm{~cm}$ de material areno-argiloso ou foram feitas a substituição destes por tubos de choque. Porém o acessório utilizado na coluna de cada furo continua sendo o cordel NP10, o que causa a expulsão dos tampões. Após a coleta dos dados em campo, eles são digitalizados e arquivados para, posteriormente, serem analisados.

Os dados coletados pelos microssismógrafos são transferidos ao computador, via cabo, até o programa GeoSonicsInc.Analysis 8.2., desenvolvido pela própria empresa que fabrica o microssismógrafo, gerando automaticamente relatórios e gráficos de relação entre velocidade de vibração de pico de partícula e frequência, além do comportamento das ondas de vibração e sobrepressão acústicas dos eventos monitorados. Nas Figuras 6 e 7 são apresentados os mapas com a localização dos pontos de monitoramento em ambas as campanhas, enquanto a Figura 8 apresenta um relatório típico de um dos eventos monitorados com as intensidades de vibração em cada eixo ortogonal, além da onda de sobrepressão acústica.

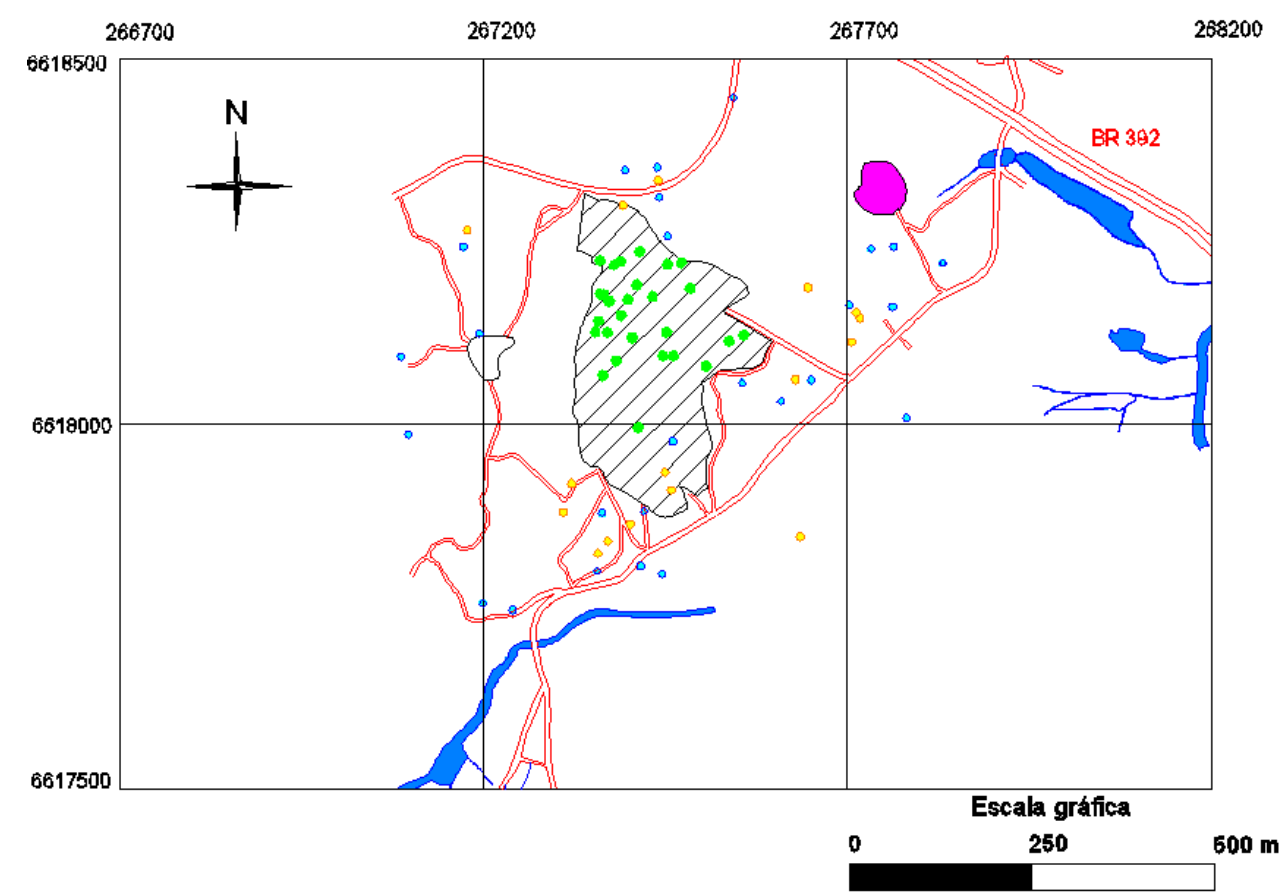

Figura 6 - Localização da mina da Corticeira e dos pontos nela monitorados (coordenadas UTM). 


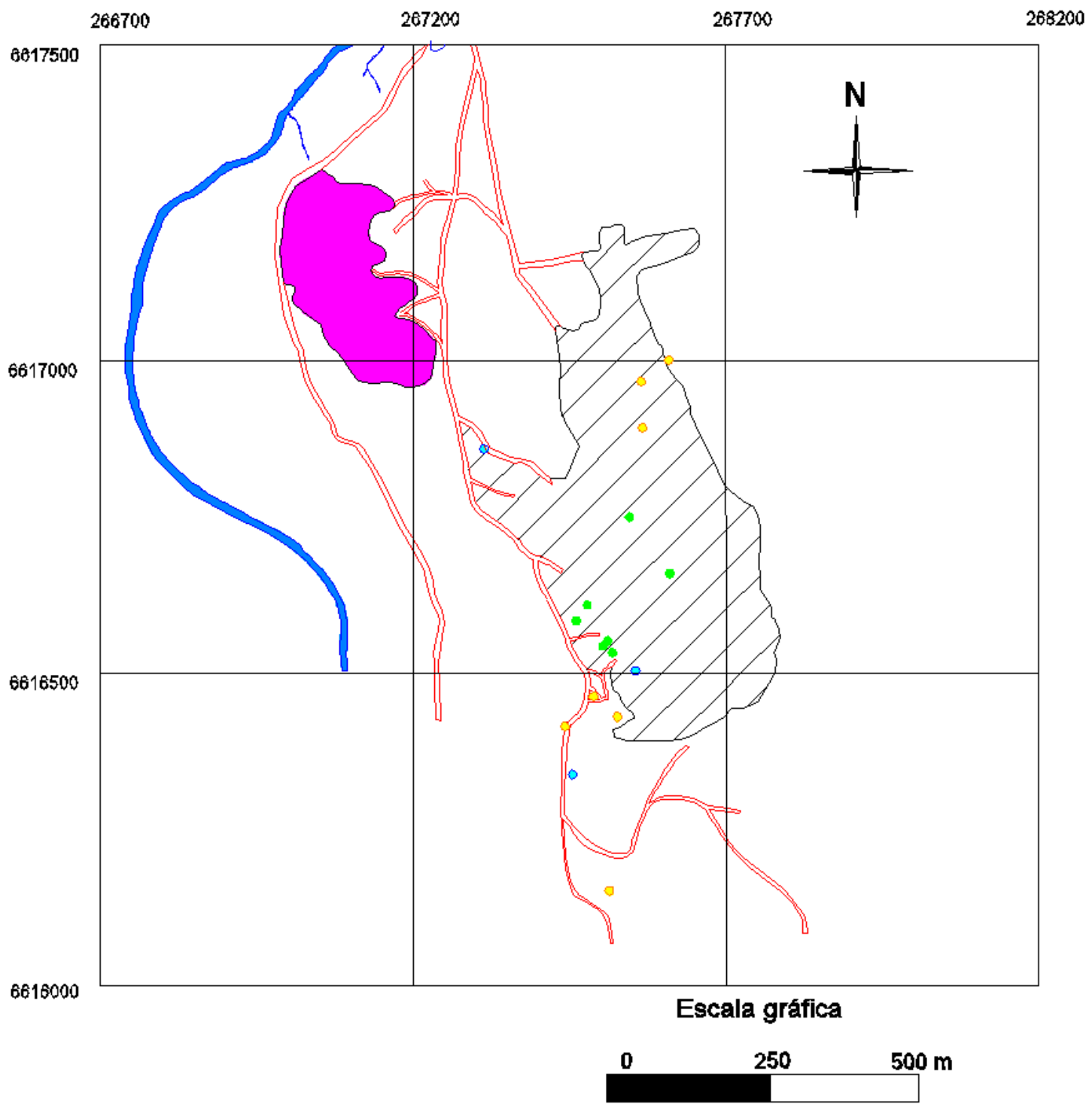

Figura 7 - Llocalização da mina do Mangueirão e dos pontos, nela monitorados (coordenadas UTM).

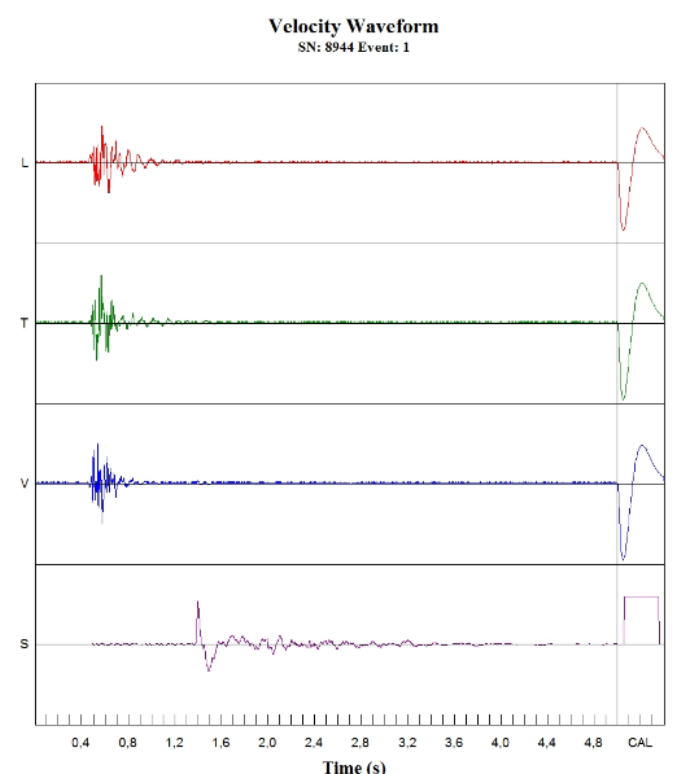

Figura 8 - Ondas de vibração (longitudinal em vermelho, transversal em verde e vertical em azul) e ruído (roxo) em função do tempo. 


\section{Análises dos Resultados}

Ao relacionar os dados de acordo com a NBR 9653 de 2005 (Figura 9), pode-se observar que todos os dados respeitam os limites da norma, com exceção de um $(5,80 \mathrm{~Hz}$ e $37,15 \mathrm{~mm} / \mathrm{s})$. A razão deste dado estar acima da norma é de que a geologia no local do monitoramento facilita a formação do fenômeno de cargas cooperativas. Na Figura 10 estão detalhados os locais onde foram feitos quatro monitoramentos da segunda campanha, e onde dois deles tiveram vibrações relativamente altas.

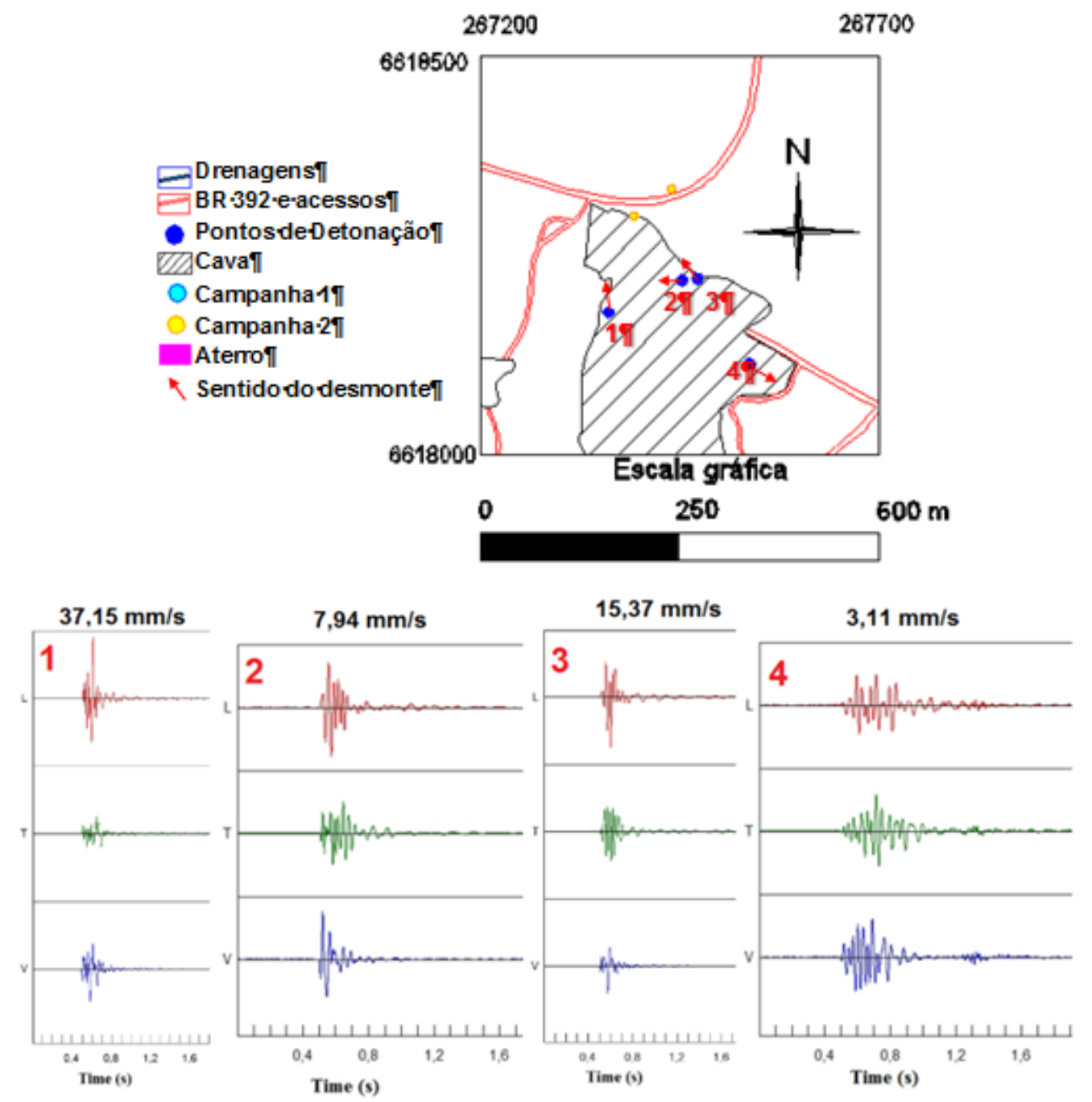

Figura 10 - Acima, o local onde foram encontrados monitoramentos com altas vibrações (somente o ponto 1 foi monitorado no ponto de coleta mais ao sul) e os respectivos relatórios sismológicos e velocidades de pico de partícula.

Neste local foi feita uma análise sismológica das ondas e foi observada uma amplitude anômala para um desmonte. Na figura 10 podemos observar algumas amplitudes maiores que chegam a se afastar mais do que seria considerado de um comportamento normal nos desmontes 1 e 3 . Comparando-se com as ondas dos outros eixos, elas possuem uma amplitude de pico bem maior. Já os monitoramentos 2 e 4 possuem uma amplitude de pico um pouco maior somente, não havendo uma amplitudes sobressalentes em nenhum dos eixos, porém, a velocidade de pico de partícula destes desmontes não é tão alta como a dos outros.

Uma explicação para essas amplitudes de pico se comportarem de uma maneira anormal ao de um comportamento típico de um desmonte de rochas seria a de que as ondas estariam se somando umas as outras, resultando em vibrações de pico de partícula bem mais altos de que realmente seriam sem 
interferências das ondas entre si. Logo o monitoramento $(5,80 \mathrm{~Hz}$ e $37,15 \mathrm{~mm} / \mathrm{s})$ ultrapassou os limites da norma por causa de cargas cooperativas e isto é justificado ainda na Figura 10, onde pode-se observar os sentidos dos desmontes: os que tem amplitudes anômalas são os que possuem o sentido do desmonte apontado para os pontos de coleta.

Outro ponto relevante envolve os desmontes que utilizaram o tubo de choque na ligação dos furos, estes obtiveram vibrações baixas como apresenta a Tabela 2. O resultado da vibração baixa já era esperado, pois este tipo acessório retarda furo por furo, diminuindo a carga máxima por espera e, consequentemente, aumentando o valor da distância escalonada e diminuindo as ondas de vibração.

Tabela 2: Resultado dos monitoramentos dos desmontes que utilizaram tudo de choque como acessório de ligação. No dia oito de Julho foram monitorados dois desmonte, o que está sendo considerado é o 1.

\begin{tabular}{|c|c|c|c|c|}
\hline DATA & SISMÓGRAFO & $\operatorname{PPV}(\mathrm{mm} / \mathrm{s})$ & $\begin{array}{l}\text { FREQ. DE } \\
\text { PICO (Hz) }\end{array}$ & $\begin{array}{c}\text { DISTÂNCIA } \\
\text { ESCALONADA } \\
\left(\mathrm{m} / \mathrm{kg}^{\wedge 0,5}\right)\end{array}$ \\
\hline \multirow{2}{*}{$12 / 12 / 2013$} & 2 & 1.71 & 26.30 & 37.63 \\
\hline & 1 & 4.38 & 22.70 & 31.60 \\
\hline \multirow{2}{*}{$06 / 02 / 2014$} & 1 & 2.92 & 17.90 & 38.19 \\
\hline & 2 & 4.25 & 20.00 & 45.40 \\
\hline $11 / 02 / 2014$ & 3 & 3.05 & 62.50 & 34.07 \\
\hline \multirow{2}{*}{$12 / 03 / 2014$} & 1 & 1.78 & 14.30 & 31.14 \\
\hline & 2 & 4.38 & 21.70 & 16.74 \\
\hline \multirow{2}{*}{$25 / 04 / 2014$} & 2 & 0.83 & 17.90 & 53.32 \\
\hline & 3 & 5.21 & 18.50 & 14.01 \\
\hline 09/05/2014 & 2 & 1.97 & 19.20 & 30.79 \\
\hline \multirow{3}{*}{ 08/07/2014 } & 1 & 2.22 & 55.60 & 25.02 \\
\hline & 2 & 3.37 & 50.00 & 21.18 \\
\hline & 3 & 1.59 & 26.30 & 29.87 \\
\hline
\end{tabular}

Também foi feito um modelo de regressão para a previsão das vibrações de pico de partícula (Figura

11). Pode se observar que as campanhas 1 e 2 obtiveram linhas de previsão de $50 \%$ de precisão diferentes, porém as de $95 \%$ de precisão mostraram-se bem similares. Este tipo de previsão considera somente o PPV, a distância entre o desmonte e o ponto monitorado e a carga máxima por espera. $\mathrm{O}$ ponto que está acima da linha de previsão de $95 \%$ é o mesmo que está acima da norma, pelos motivos explicados anteriormente.

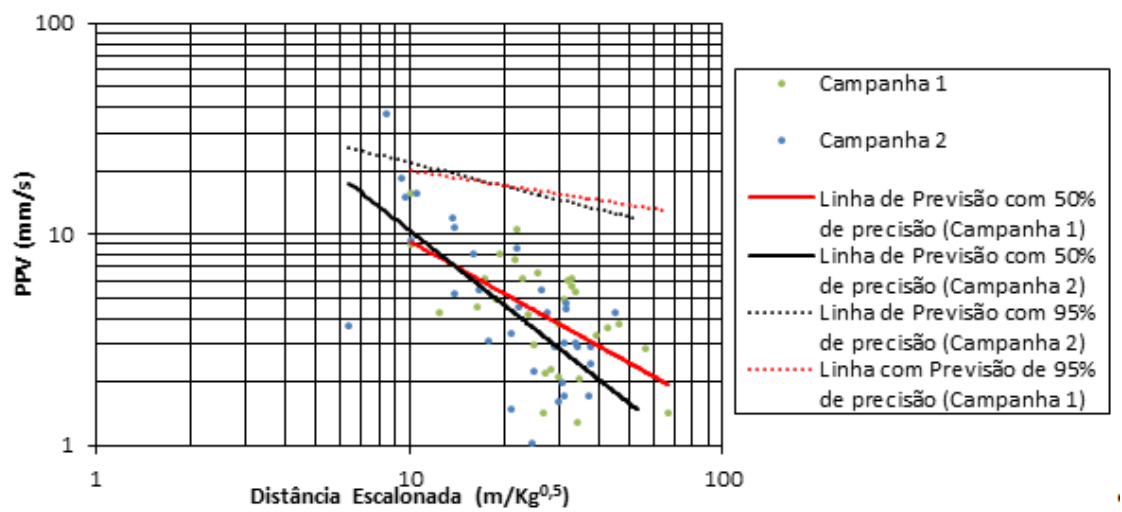

Figura 11 - Modelo de regressão com linhas de previsão com precisão de $95 \%$ e 50\%. 
Na figura 12 está apresentada a relação entre ruído e a distância escalonada de ambas as campanhas. Pode-se observar que, por mais que o cordel tenha sido coberto com material arenoargiloso ou trocado por tubos de choque, a segunda campanha não obteve o resultado desejado. Dez dos ruídos monitorados, dois a mais do que os da primeira campanha, ultrapassaram o limite da NBR 9653:2005 que é abaixo de 134 decibéis.

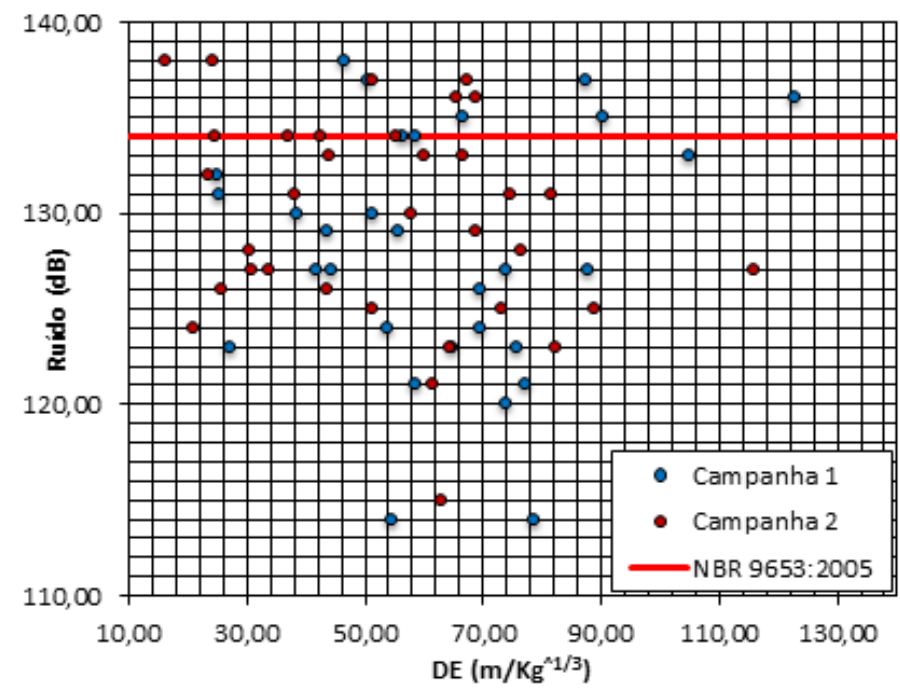

Figura 12 - Dados de ambas as campanhas plotados em uma relação de ruído ( $\mathrm{mm} / \mathrm{s})$ e distância escalonada $\left(\mathrm{m} / \mathrm{Kg}^{1 / 3}\right)$. Abaixo da linha vermelha é o limite permitido para as vibrações pela NBR 9653:2005 que é inferior a $134 \mathrm{~dB}$.

Através de diversas análises comparativas, encontrou-se o que foi a principal causa desses ruídos, os desmontes secundários, principalmente, quando se detona matacões. A explicação é dada pelos pulsos de liberação de gases e a falta de tampão apropriado para esta finalidade, além de não ser possível cobrir o cordel nestes casos (Figura 13). Os desmontes secundários muitas vezes têm várias faces livres, não dando um grau de confinamento adequando para a respectiva quantidade de explosivo. Isto ocasiona um fraturamento muito grande da rocha e deixa escapar uma grande quantidade de gás proveniente da decomposição do explosivo. O efeito é mais intenso ainda em matacões, pois possuem faces livres por todo seu entorno.

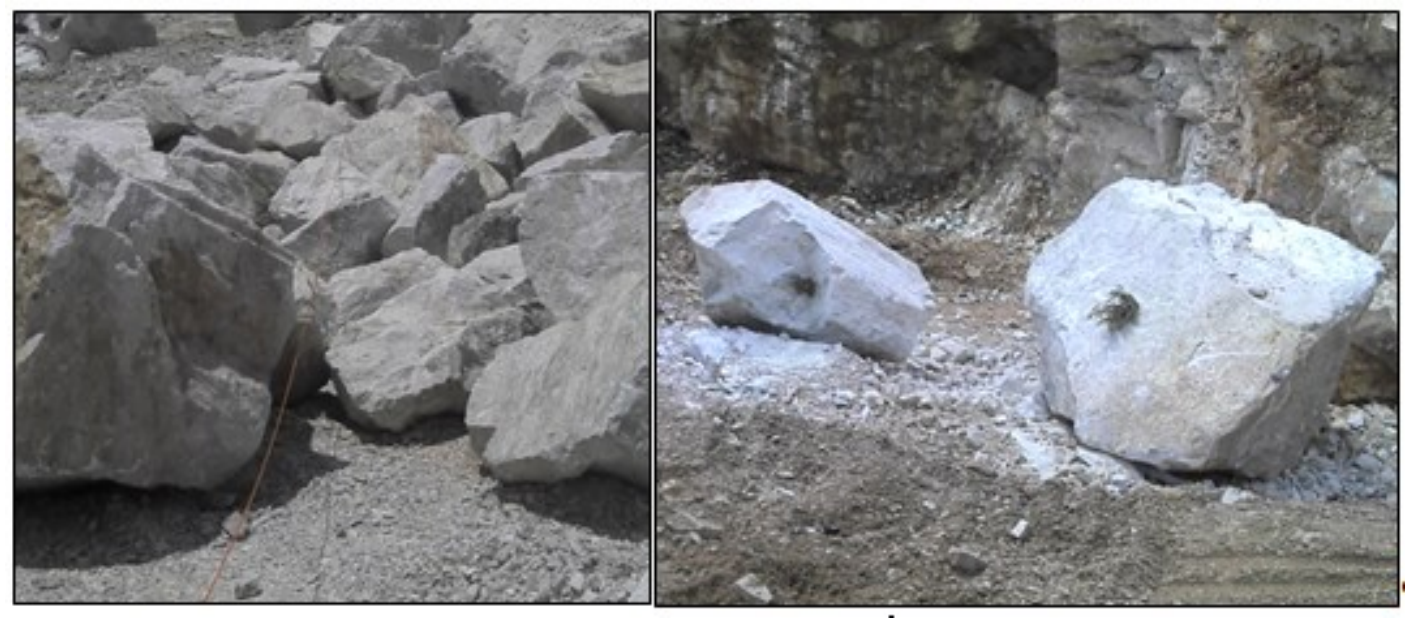

Figura 13 - Cordel exposto (à esquerda) e matacões marcados para desmonte secundário com os respectivos tampões.

Além disto, a grande maioria das vezes é utilizado um ramo de folhas como tampão em furos de desmontes secundários, não sendo nada eficientes como acessórios de confinamento. Isto causa um grande escape de gás pelo próprio furo, tendo o mesmo efeito de um canhão sem projétil sendo acionado (Figura 13). 
Na Tabela 3 pode-se observar que nenhum dos desmontes que continham matacões ficou abaixo de 134 decibéis. Também é possível notar que todos os desmontes livres de secundários tinham ruídos de acordo com a norma. Os desmontes que não contem matacões podem ou não passar o limite da norma, isto depende do grau de confinamento na rocha. Na figura 14 é possível notar as diferenças entre as intensidades da sobrepressão acústica através do tamanho dos respectivos círculos. Já na Figura 15 está o modelo de atenuação do ruído. Pode-se observar que dois pontos monitorados na campanha 1 ultrapassam as linhas de tendência (95\% de previsão), isto acontece por causa do erro no cálculo da carga máxima por espera.

Tabela 3: Dados de fundo verde são os que estão abaixo de 134 decibéis, os que estão em fundo vermelho ultrapassaram este limite. Os números após algumas das datas são as identificações de desmontes que foram monitorados no mesmo dia.

\begin{tabular}{|c|c|c|c|c|c|}
\hline DATA & SISMÓGRAFO & RUÍDO & $\begin{array}{l}\text { SOBREPRESSÃO } \\
\text { ACÚSTICA(PSI) }\end{array}$ & \begin{tabular}{|c|} 
DESMONTES \\
SECUNDÁRIOS \\
\end{tabular} & $\begin{array}{c}\text { COM } \\
\text { MATACÕES }\end{array}$ \\
\hline \multirow{2}{*}{$26 / 11 / 2013$} & 1 & 130 & 0,0091706050 & $\mathrm{NÃO}$ & $\mathrm{NÃO}$ \\
\hline & 2 & 123 & 0,0040963590 & $\mathrm{NÃO}$ & $\mathrm{NÃO}$ \\
\hline \multirow{2}{*}{$29 / 11 / 2013$} & 2 & 134 & 0,0145344300 & SIM & 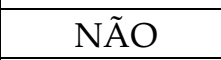 \\
\hline & 3 & 134 & 0,0145344300 & SIM & $\mathrm{NÃO}$ \\
\hline \multirow{2}{*}{$02 / 12 / 2013$} & 3 & 137 & 0,0205304280 & SIM & SIM \\
\hline & 2 & 138 & 0,0230355190 & SIM & SIM \\
\hline \multirow{2}{*}{$12 / 12 / 2013$} & 2 & 128 & 0,0072844710 & $\mathrm{NÃO}$ & $\mathrm{NÃO}$ \\
\hline & 1 & 123 & 0,0040963590 & $\mathrm{NÃO}$ & NÃO \\
\hline $04 / 02 / 2014$ & 1 & 115 & 0,0016307900 & $\mathrm{NÃO}$ & NÃO \\
\hline \multirow{2}{*}{$06 / 02 / 2014$} & 1 & 131 & 0,0102895880 & SIM & $\mathrm{NÃO}$ \\
\hline & 2 & 125 & 0,0051570100 & SIM & NÃO \\
\hline $11 / 02 / 2014$ & 3 & 125 & 0,0051570100 & SIM & $\mathrm{NÃO}$ \\
\hline \multirow{2}{*}{$14 / 02 / 2014$} & 1 & 124 & 0,0045961900 & $\mathrm{NÃO}$ & $\mathrm{NÃO}$ \\
\hline & 2 & 127 & 0,0064922910 & $\mathrm{NÃO}$ & $\mathrm{NÃO}$ \\
\hline \multirow{2}{*}{$12 / 03 / 2014$} & 1 & 129 & 0,0081733110 & SIM & $\mathrm{NÃO}$ \\
\hline & 2 & 134 & 0,0145344300 & SIM & NÃO \\
\hline \multirow{2}{*}{$25 / 04 / 2014$} & 2 & 127 & 0,0064922910 & $\mathrm{NÃO}$ & $\mathrm{NÃO}$ \\
\hline & 3 & 128 & 0,0072844710 & NÃO & $\mathrm{NÃO}$ \\
\hline $28 / 04 / 2014$ & 2 & 132 & 0,0115451080 & $\mathrm{NÃO}$ & $\mathrm{NA} O$ \\
\hline \multirow{2}{*}{$\begin{array}{c}07 / 05 / 2014 \\
\text { (1) }\end{array}$} & 2 & 134 & 0,0145344300 & SIM & SIM \\
\hline & 3 & 138 & 0,0230355190 & SIM & SIM \\
\hline \multirow{2}{*}{$\begin{array}{c}07 / 05 / 2014 \\
(2)\end{array}$} & 1 & 136 & 0,0182977630 & SIM & $\mathrm{NA} O$ \\
\hline & 2 & 127 & 0,0064922910 & SIM & $\mathrm{NÃO}$ \\
\hline \multirow{2}{*}{$\begin{array}{c}08 / 05 / 2014 \\
\text { (1) }\end{array}$} & 1 & 126 & 0,0057862610 & SIM & $\mathrm{NÃO}$ \\
\hline & 2 & 131 & 0,0102895880 & SIM & $\mathrm{NÃO}$ \\
\hline \multirow{2}{*}{$\begin{array}{c}08 / 05 / 2014 \\
\text { (2) }\end{array}$} & 1 & 133 & 0,0129538240 & SIM & $\mathrm{NÃO}$ \\
\hline & 2 & 131 & 0,0102895880 & SIM & $\mathrm{NÃO}$ \\
\hline $09 / 05 / 2014$ & 2 & 136 & 0,0182977630 & SIM & SIM \\
\hline \multirow{3}{*}{$\begin{array}{c}08 / 07 / 2014 \\
(1)\end{array}$} & 1 & 125 & 0,0051570100 & SIM & NÃO \\
\hline & 2 & 126 & 0,0057862610 & SIM & $\mathrm{NÃO}$ \\
\hline & 3 & 121 & 0,0032538540 & SIM & $\mathrm{NÃO}$ \\
\hline \multirow{3}{*}{$\begin{array}{c}08 / 07 / 2014 \\
\text { (2) }\end{array}$} & 1 & 137 & 0,0205304280 & SIM & $\mathrm{NÃO}$ \\
\hline & 2 & 133 & 0,0129538240 & SIM & $\mathrm{NÃO}$ \\
\hline & 3 & 133 & 0,0129538240 & SIM & $\mathrm{NÃO}$ \\
\hline
\end{tabular}


Mina da Corticeira

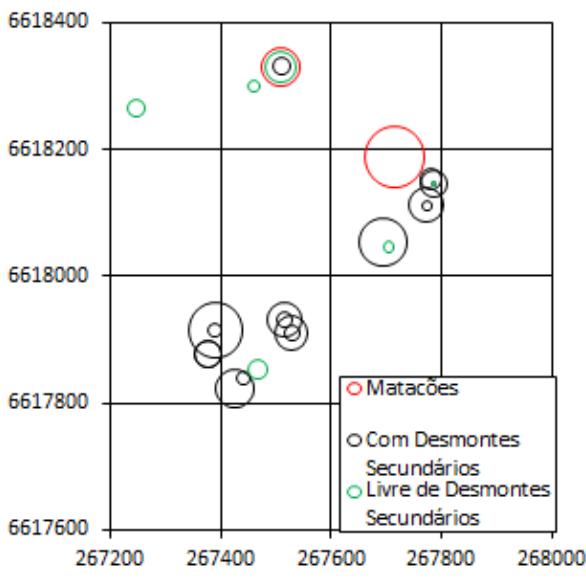

Mina do Mangueirão

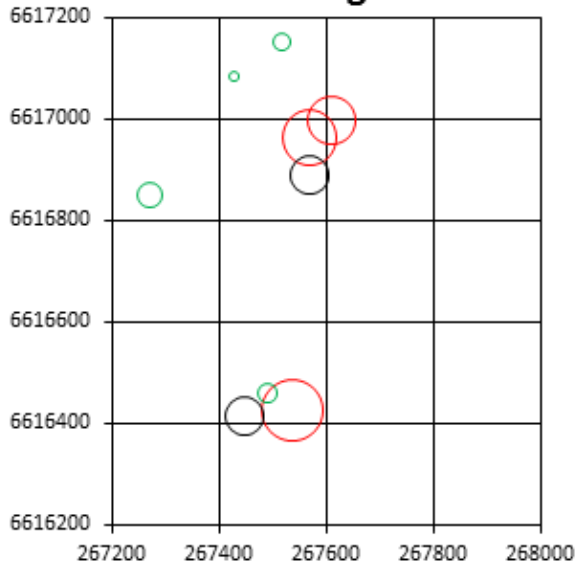

Figura 14 - Localização (coordenadas UTM) dos pontos de monitoramento na mina da Corticeira e do Mangueirão. Quanto maior o diâmetro do círculo, maior o valor da sobrepressão acústica (psi) do monitoramento.

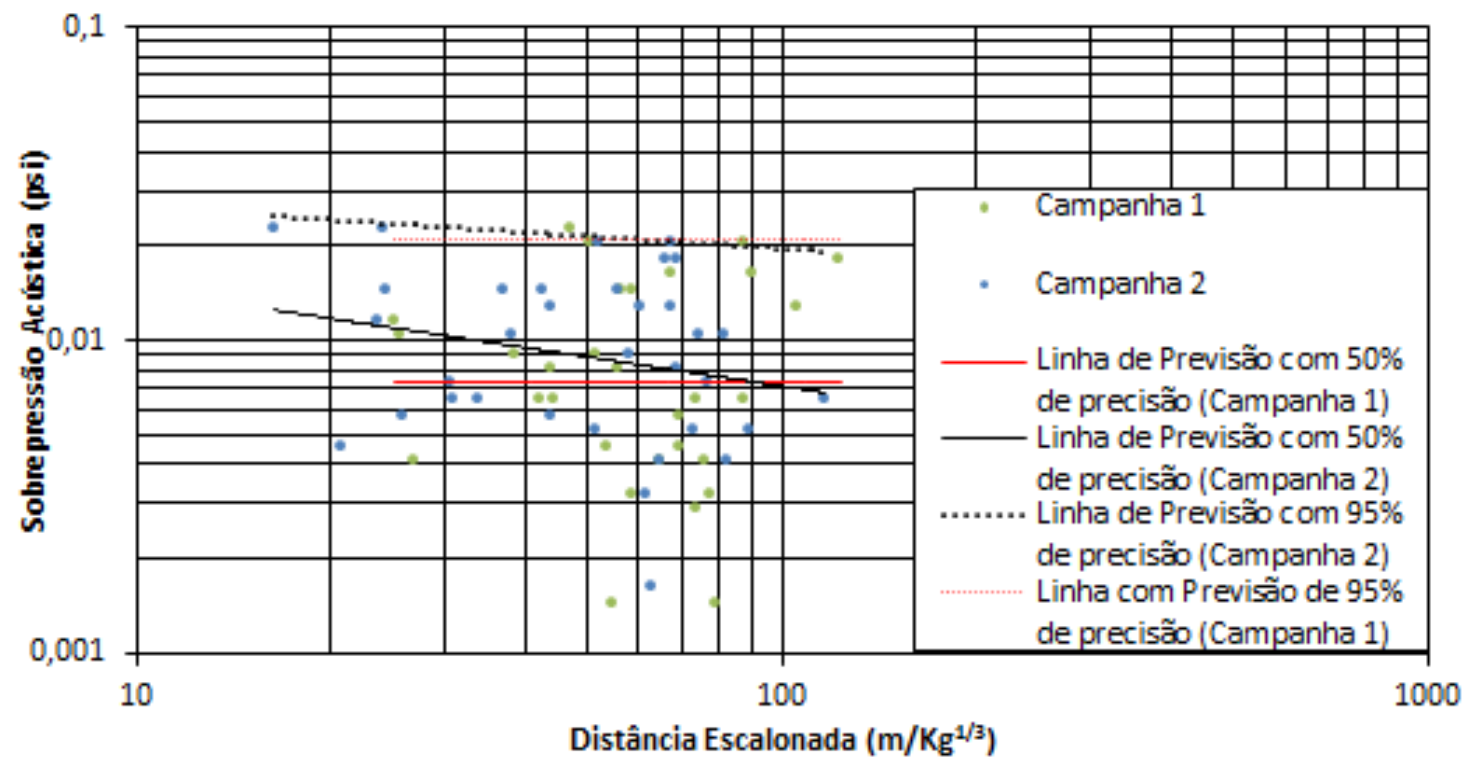

Figura 15 - Modelo de regressão com linha de previsão com precisão de 95\% para sobrepressão acústica.

\section{Conclusão}

Ao se analisar as vibrações, pode-se concluir que, com exceção de um caso, elas respeitam a norma, independente do plano de fogo e dos acessórios neles utilizados. Através do modelo de regressão linear pode-se prever as vibrações, servindo como parâmetro para elaboração dos planos de fogo da empresa. Embora o modelo de regressão da campanha 1 seja próxima ao da campanha 2, ela não tem um grau de confiança tão grande, pois as cargas máximas por espera não foram pesadas, o que torna, como mostra a Tabela 1, os dados estimados não confiáveis. Porém, mesmo obtendo um modelo de previsão mais confiável, ainda há a chance de ocorrer o fenômeno de cargas cooperativas, que pode elevar os níveis de vibração, ultrapassando a linha de previsão com $95 \%$ de precisão, como é o caso do ponto $(5,80 \mathrm{~Hz} / 37,15 \mathrm{~mm} / \mathrm{s})$ da Figura 9. Casos como esse podem ser evitados de duas maneiras:

(i) diminuindo a carga máxima por espera através da utilização dos tubos de choque. A Tabela 2 mostra que a utilização deste tipo de acessórios tem mostrados níveis de vibração mais baixos;

(ii) mudando o sentido do desmonte para locais onde não haja riscos de danos ambientais, evitando que o fenômeno ocorra em áreas indesejáveis. 
Os ruídos mostraram-se ir além da norma várias vezes (Figura 12). Através da Tabela 3 e da Figura 14 pode-se observar que os desmontes secundários têm grande influência nos altos níveis de ruído, principalmente os que contêm matacões. Isto acontece pelo fato dos desmontes secundários não apresentarem a possibilidade do isolamento acústico do cordel, através da camada areno-argilosa, e por apresentarem mais faces livres, facilitando o pulso de libração de gases, que aumentam os níveis dos ruídos. Além disto, os tampões utilizados nestes desmontes secundários não são apropriados, não fornecendo um confinamento adequado para os explosivos, causando a ejeção de si mesmos e do aumento dos ruídos. Diante desta situação, são necessárias mudanças para diminuir os ruídos:

(i) mudanças nos afastamentos, espaçamentos e, se possível, no diâmetro do furos. Uma mudança no plano de fogo deve ser feita a fim de se obter uma maior fragmentação e diminuir o número de desmontes secundários, já que estes são muito frequentes.

(ii) alterar o tipo de tampão, utilizando brita ou outro material adequado para tamponar os furos e dar melhor confinamento.

(iii) substituição dos cordéis como acessórios de coluna por tubos de choque de coluna, evitando a ejeção dos tampões.

O modelo de previsão do ruído (Figura 15) é confiável somente para a campanha 2, pois, assim como justificado no modelo para as vibrações, as cargas máximas por espera da campanha 1 não são confiáveis.

Contudo, há mais um fator que influencia os impactos do desmonte de rochas. A empresa explora a jazida de maneira predatória, procurando teores mais favoráveis para a calcinação. Desta maneira, o planejamento de lavra acaba por, praticamente, não existir. Por causa disto, os desmontes são feitos à maneira prática, onde são estimados e, pela grande demanda na usina de beneficiamento, muitas vezes são feitos sem os devidos cuidados: furos entupidos que impossibilitam o carregamento, a perfuração acaba não sendo simétrica e não há malha de fogo pré-definida. Cabe à empresa investir em uma racionalização da jazida, pré-estabelecendo os pontos de detonações, as malhas que serão utilizadas, de quanto será sua produção e quando serão feitas.

\section{Referências}

ADHIKARI; G.R. Role of blast design parameters on ground vibration and correlation of vibration level to blasting damage to surface structures. SET Project: MT/134/02. Kolar Gold Fields, Karnataka, 2005.2 Disponível em: $<$ http://www.osmre.gov/resources/blasting/docs/Intl/NirmVibReport.pdf $>$. Acesso em 10 de jun. de 2014.

BANDHARI; S. Engineering Rock Blasting Operations. Rotherdam, Netherlands: A. A. Balkema, 375 p., 1997.

CONESTOGA-ROVERS \& ASSOCIATES. Blasting Impact Assessment: Future Blasting Operations At The Moose River Open Pit Gold Mine Development Site. Touquoy Gold Project. Waterloo, Ontario, 2007.

DORNELES, F. T. Controle e Previsão de Vibrações e Ruídos Gerados Por Desmonte de Rochas Com Explosivos. Universdade Federal do Pampa. Trabalho de Conclusão de Curso. Caçapava do Sul, 2013.

FERREIRA, G. D; DALLORA NETO, C. Controle de Vibrações Geradas por Desmonte de Rocha com Explosivos Estudo de Caso: Calcário Cruzeiro Limeira (SP). Departamento de Geologia Aplicada, Instituto de Geociências e Ciências Exatas, Universidade Estadual Paulista, Campus de Rio Claro. Rio Claro, São Paulo, 2006. 
KOPPE, J. C; MUNARETTI, E; COSTA, J. F. C. L; FEIJÓ, J. F. L. Estudo da Utilização de ANFO na Mina de Carvão do Recreio, Butiá, RS. Brasil Mining Site. Sem endereço físico, 2008. Disponível em: $<\quad$ http://www.brasilminingsite.com.br/includes/modulos/mdl_artigo/exibir_artigo.php?id=14>. Acessado em 31 de jun. 2014.

MUNARETTI, E; KOPPE, J. C; SALVADORETTI; P; COSTA, J. F. C. L. Monitoramento Geofísico De Desmonte De Rocha Com Utilização De Explosivos Em Condições De Risco Elevado Em Zona Urbana. Gouvêa \& Gouvêa. Jandira, São Paulo, (2001). Disponível em $<$ http://www.desmontederochas.com.br/index.php?option=com_content\&view=article\&id=86:desmo nte-de-rochas-monitoramento-geofisico-de-desmonte-de-rocha-com-utilizacao-de-explosivos-emcondicoes-de-risco-elevado-em-zona-urbana\&catid=35:artigos-sobre-desmonte-de-rochas-a-friodesmonte-de-rocha-com-fio-corte-em-rochas\&Itemid=123>. Acessado em 9 de mar. 2014.

NBR 9653:2005 - Guia para avaliação dos efeitos provocados pelo uso de explosivos nas minerações em áreas urbanas.NRM 16 - Operações Com Explosivos e Acessórios.

PERSSON, P. A; HOLMBERG, R.; LEE, J. Rock Blasting and Explosives Engineering. Boca Raton, Florida: CCR Press, 531 p., 1994;

PORCHER, C. A.; LOPES, R. C; J. A. FONSECA. Programa Levantamentos Geológicos Básicos do Brasil. Ministério de Minas e Energia, Companhia de Pesquisa de Recursos Minerais - CPRM. Cachoeira do Sul, Folha SH.22-Y-A. Brasília, Distrito Federal, 2000.

ROSENHAIM, V. L; MUNARETTI, E; KUCKARTZ, B. T.; MENDONÇA, C. S. Análise de Iniciação com Espoleta Eletrônica Para Produção de Agregados no RS. Nitro Ltda, Porto Alegre, Rio Grande do Sul, 2012. Disponível em: <http://www.nitro-rs.com.br/TEXTO1.pdf>. Acesso em 10 fev. 2014.

SCLIAR, C. Mineração e Geodiversidade do Planeta Terra. São Paulo, São Paulo: Signus Editora LTDA, 96 p., 2009.

U.S. ARMY CORPS OF ENGINEERS. Geophysical Exploration For Engineering and Environmental Investigations. U.S. Army Corps of Engineers. District Columbia, Washington, 31 aug. 1995.

Disponível em: http://www.publications.usace.army.mil/Portals/76/Publications/EngineerManuals/EM_1110-11802.pdf >. Acesso em 1 aug. 2014. 